University of Wollongong

Research Online

Faculty of Engineering and Information

Faculty of Engineering and Information

Sciences - Papers: Part A

Sciences

$1-1-2014$

Rejection of trace organic chemicals by a hollow fibre cellulose triacetate reverse osmosis membrane

Takahiro Fujioka

University of Wollongong, takahiro@uow.edu.au

Stuart J. Khan

University of New South Wales, s.khan@unsw.edu.au

James A. McDonald

University of New South Wales

Long D. Nghiem

University of Wollongong, longn@uow.edu.au

Follow this and additional works at: https://ro.uow.edu.au/eispapers

Part of the Engineering Commons, and the Science and Technology Studies Commons

Research Online is the open access institutional repository for the University of Wollongong. For further information contact the UOW Library: research-pubs@uow.edu.au 


\title{
Rejection of trace organic chemicals by a hollow fibre cellulose triacetate reverse osmosis membrane
}

\author{
Abstract \\ The rejection behaviours of 41 trace organic chemicals (TrOCs) by a hollow fibre cellulose triacetate \\ (CTA) reverse osmosis (RO) membrane for potable water reuse were evaluated. Results reported here \\ suggest that the rejection behaviours of TrOCs by the CTA RO membrane are mostly similar to those \\ previously reported for the polyamide (PA) RO membrane. However, in comparison to the PA based RO \\ membrane, hydrophobic interaction plays a greater role while electrostatic interaction is less significant in \\ governing the rejection of TrOCs by the CTA RO membrane. No difference in rejection between positively \\ and negatively charged compounds by the CTA RO membrane could be observed. The rejection of neutral \\ TrOCs by the CTA RO membrane varied significantly from $25 \%$ to over $95 \%$. Molecular size (i.e. minimum \\ projection area) was found to be an important factor governing the rejection of neutral TrOCs. Further \\ investigation using $\mathrm{N}$-nitrosamines reveals that in addition to molecular size, hydrophobicity could \\ significantly influence their rejection by the CTA RO membrane, while N-nitrosamine rejection by the PA \\ RO membrane was mostly governed by molecular size. In contrast to the neutral TrOCs, most charged \\ TrOCs selected in this investigation exhibited over $90 \%$ rejection, regardless of molecular size.

\section{Disciplines \\ Engineering | Science and Technology Studies}

\section{Publication Details} \\ Fujioka, T., Khan, S. J., McDonald, J. A. \& Nghiem, L. D. (2015). Rejection of trace organic chemicals by a \\ hollow fibre cellulose triacetate reverse osmosis membrane. Desalination, 368 69-75.
}




\title{
Rejection of trace organic chemicals by a hollow fibre cellulose triacetate reverse osmosis membrane
}

\author{
Revised manuscript submitted to
}

\section{Desalination}

May 2014

Takahiro Fujioka ${ }^{1, *}$, Stuart J. Khan ${ }^{2}$, James A. McDonald ${ }^{2}$, Long D. Nghiem ${ }^{1}$

${ }^{1}$ Strategic Water Infrastructure Laboratory, School of Civil Mining and Environmental Engineering, The University of Wollongong, NSW 2522, Australia

${ }^{2}$ UNSW Water Research Centre, School of Civil and Environmental Engineering, The University of New South Wales, NSW 2052, Australia 


\section{$1 \quad$ Abstract}

2 The rejection behaviours of 41 trace organic chemicals (TrOCs) by a hollow fibre cellulose 3 triacetate (CTA) reverse osmosis (RO) membrane for potable water reuse were evaluated. 4 Results reported here suggest that the rejection behaviours of TrOCs by the CTA RO 5 membrane are mostly similar to those previously reported for polyamide (PA) RO 6 membrane. However, in comparison to PA based RO membrane, hydrophobic interaction 7 plays a greater role while electrostatic interaction is less significant in governing the 8 rejection of TrOCs by the CTA RO membrane. No difference in rejection between 9 positively and negatively charged compounds by the CTA RO membrane could be 10 observed. The rejection of neutral TrOCs by the CTA RO membrane varied significantly 11 from $25 \%$ to over $95 \%$. Molecular size (i.e. minimum projection area) was found to be an 12 important factor governing the rejection of neutral TrOCs. Further investigation using N13 nitrosamines reveals that in addition to molecular size, hydrophobicity could significantly 14 influence their rejection by the CTA RO membrane, while N-nitrosamine rejection by PA 15 RO membrane was mostly governed by molecular size. In contrast to the neutral TrOCs, 16 most charged TrOCs selected in this investigation exhibited over $90 \%$ rejection, regardless 17 of molecular size.

18 Keywords: Potable water reuse, trace organic chemicals, N-nitrosamines, reverse osmosis, 19 cellulose triacetate membrane. 


\section{Introduction}

Wastewater reclamation for potable reuse is an important practice to enhance the security of water supplies in many arid or densely populated areas [1]. This practice is in contrast to the conventional approach whereby potable water is to be sourced from a protected natural water body. Thus, potable water reuse is commonly subjected to very stringent treatment requirements to achieve satisfactory removal of a diverse range of contaminants known to occur in raw and conventionally treated wastewater. These include many trace organic chemicals (TrOCs) that may cause chronic health impacts to the public.

In a growing number of modern water reclamation plants, the removal of TrOCs is achieved mostly by the reverse osmosis (RO) filtration process. In fact, RO membrane has been recognised as reliable barrier for removing most TrOCs that may occur in secondary treated effluent [2]. Most, if not all, of these water reclamation plants use polyamide (PA) or PA-derivative RO membranes that can offer high permeate flux and adequate salt rejection [3]. However, PA RO membranes are not chemically resilient to strong oxidising agents such as free chlorine which has a high potential of controlling biofouling. For example, PA RO membrane can be degraded by chlorine [4, 5]. All PA RO membrane manufacturers have specified a chlorine limit of about $200-1,000 \mathrm{mg} / \mathrm{L}-$ hours. As a result, monochloramine which is a less powerful oxidant than chlorine in terms of disinfection performance is used to control biofouling. Thus, their applications to feed solution with a high fouling potential may entail undesirable complications. Moreover, depending on the system configuration, N-nitrosodimethylamine (NDMA) and other N-nitrosamines, which are an important group of disinfection by-products, can be formed during the formation of chloramines from chlorine [6]. At several full-scale water reclamation plants using RO, the concentrations of NDMA in the RO permeate were detected at concentrations higher than value (e.g. $10 \mathrm{ng} / \mathrm{L}$ ) regulated or recommended by health authorities, leading to the installation of advanced oxidation post treatment for further NDMA removal $[6,7]$. It is also noteworthy that NDMA rejections by PA RO membranes reported from pilot- and full-scale RO systems were low and variable in the range from $10 \%$ to $60 \%$ [6-10]. In this instance, chlorine resistant membranes would allow for the use of chlorine to control biofouling with significantly less NDMA formation [11].

In recent years, cellulose acetate (CA) and cellulose triacetate (CTA) have re-emerged as an attractive material to fabricate RO membranes especially for feed water with high 

permeability and can be operated in a much wider $\mathrm{pH}$ range [12]. Nevertheless, CTA RO membranes are chlorine-resistant and thus residual chlorine can be maintained at up to 1 $\mathrm{mg} / \mathrm{L}$ in the RO feed [13]. In fact, the CTA RO filtration in combination with chlorination can suppress biological growth on RO membrane surfaces and prevent an increase in feed pressure caused by membrane fouling in seawater desalination applications [14-17]. Thus, RO filtration using CTA RO membranes potentially has an advantage over PA-based thinfilm composite RO membranes with respect to the control of biofouling and N-nitrosamine formation during water treatment. Despite its potential, knowledge regarding the rejection of TrOCs by CTA RO membranes remains scarce. There have only been a few studies on the rejection of TrOCs by CA $[18,19]$ and CTA [20] membranes. Only six TrOCs were investigated in these studies and the experiments were conducted using small flat sheet membrane samples. Given the need for chlorine resistant RO membranes, CTA based membranes are expected to play a greater role in water recycling applications. Thus, a comprehensive understanding of TrOC rejection by CTA RO membranes is essential for their application for potable water reuse.

The aim of this work was to assess the rejection behaviour of TrOCs by a CTA RO membrane. The rejection of a range of TrOCs by a hollow fibre CTA RO membrane was examined using a laboratory-scale RO filtration unit. The study also aimed to elucidate physicochemical properties of these compounds governing their rejection by the CTA RO membrane. The rejection results obtained here were directly compared with those observed for a PA RO membrane.

\section{Materials and methods}

\subsection{RO membrane and Bench-scale filtration system}

A cellulose triacetate hollow fibre RO membrane module for brackish water desalination (HKC3023V) supplied by Toyobo Co., Ltd. (Osaka, Japan) was used in this investigation. The hollow fibres were operated in an outside-in configuration and were bundled inside the module with a horseshoe shape (Figure 1a). Each hollow fibre was about $1 \mathrm{~m}$ in length, with outer and inner diameters of $165 \mu \mathrm{m}$ and $70 \mu \mathrm{m}$, respectively. Because of the very small fibre diameter, the contact angle and zeta potential of this membrane could be measured. However, it can be inferred from measurement using a flat sheet CTA material [21] that this hollow fibre membrane is hydrophilic and only slightly negatively charged. 
The module housing was made of a polyvinyl chloride pipe reinforced specially by steel rings. According to the manufacturer, the applied feed pressure of this module should not exceed 1.1 MPa. The HKC3023V membrane module has a total outer surface area of 22 $\mathrm{m}^{2}$. According to the manufacturer, the nominal $\mathrm{NaCl}$ rejection of this membrane evaluated under test operating conditions $(500 \mathrm{mg} / \mathrm{L} \mathrm{NaCl}$, feed pressure $=0.5 \mathrm{MPa}$, feed temperature $=25.0{ }^{\circ} \mathrm{C}$, and recovery $=30 \%$ ) is $94 \%$ (feed salinity basis). Pure water permeability of the CTA membrane determined using Milli-Q water at $1.0 \mathrm{MPa}$ was 0.38 $\mathrm{L} / \mathrm{m}^{2} \mathrm{hbar}$.

A laboratory-scale cross flow RO filtration system was used in this study (Figure 1b). The filtration system comprises a stainless steel reservoir with a $12 \mathrm{~L}$ solution capacity, high pressure pump (Hydra-Cell, Wanner Engineering Inc., Minneapolis, MN, USA) and membrane module. Permeate and cross flow rates were monitored using variable area flow meters. These flow rates were adjusted using a back pressure regulating valve and bypass valve. Feed temperature was controlled by a temperature control unit (Neslab RTE 7, Thermo Scientific Inc., Waltham, MA, USA) which is connected to a stainless steel heat exchanger coil.

\section{[Figure 1]}

\subsection{Chemicals}

A set of 41 organic chemicals was selected to represent major TrOC groups that occur widely in treated wastewater effluent. They include pharmaceutically active compounds, steroid hormones, industrial chemicals, pesticides and N-nitrosamines (Table 1). All chemicals were of analytical grade and were obtained from Sigma-Aldrich (Castle Hill, NSW, Australia). These TrOCs were categorised into four categories depending on their physiochemical properties: neutral hydrophilic $(\log D<2)$, neutral hydrophobic $(\log D \geq$ 2 ), and negatively and positively charged compounds (Table 1) $[22,23]$. The Log $D$ value is the logarithm of the apparent distribution coefficient $(D)$ which represents hydrophobic properties at an ambient $\mathrm{pH}$, accounting for ionisation. Charged compounds classified here were compounds that are dissociated by over $50 \%$ in $\mathrm{pH} 8$ solution (Supplementary Material Table S1). Minimum projection area (Table 1) is two dimensional area of the conformer projected with the minimum plane of its circular disk. Minimum projection area can be calculated based on the Van der Waals radius and can be described as the area of 
the surrounded circle in Figure 2. Among three parameters describing the size of molecules

117 (i.e. molecular weight, molecular volume and minimum projection area), minimum

118 projection area was expected to be most correlated with the retention of compounds,

119 assuming the passage of solutes (e.g. free-volume hole) within the RO membrane has a

120 circular shape. Minimum projection area has not been used in any previous literature for

121 the investigation of the correlation between compound size and their rejections. An analyte

122 stock solution of N-nitrosamines was prepared in methanol at $10 \mathrm{mg} / \mathrm{L}$. All other TrOCs

123 were included in a second analyte stock solution prepared in pure methanol at $10 \mathrm{mg} / \mathrm{L}$ of

124 each compound. An internal standard stock solution of deuterated N-nitrosamines was

125 prepared in pure methanol for isotope dilution during the analysis. Similarly, a second

126 internal standard stock solution containing deuterated isotopes of all other TrOCs was also

127 prepared in pure methanol. All deuterated compounds were from CDN isotopes (Pointe-

128 Claire, Quebec, Canada). The analyte and internal standards stock solutions were kept at -

$12918{ }^{\circ} \mathrm{C}$ in the dark and were used within 1 month of preparation. Analytical grade $\mathrm{NaCl}$,

$130 \mathrm{CaCl}_{2}$ and $\mathrm{NaHCO}_{3}$ were obtained from Ajax Finechem (Taren Point, NSW, Australia) and

131 used as the background electrolytes during the filtration experiments.

\subsection{Experimental protocols}

135 The experiment started with a stabilisation step where the filtration system was operated 136 with Milli-Q water at $1000 \mathrm{kPa}$ for three hours. The system water recovery and solution 137 temperature were maintained at $25 \%$ and $20 \pm 0.1^{\circ} \mathrm{C}$, respectively. Thereafter, the Milli-Q 138 water in the feed was replaced with $13 \mathrm{~L}$ of a solution containing background electrolytes $139\left(20 \mathrm{mM} \mathrm{NaCl}, 1 \mathrm{mM} \mathrm{CaCl}_{2}\right.$ and $\left.1 \mathrm{mM} \mathrm{NaHCO}_{3}\right)$. Unless otherwise stated, the standard $\mathrm{pH}$ 140 of 8 was used. Feed $\mathrm{pH}$ was adjusted by dosing $1 \mathrm{M} \mathrm{HCl}$ or $1 \mathrm{M} \mathrm{NaOH}$. The stock solution 141 of N-nitrosamines was spiked into the feed reservoir to obtain $250 \mathrm{ng} / \mathrm{L}$ of each N142 nitrosamine. The stock solution of the other compounds was also added to obtain $75 \mathrm{ng} / \mathrm{L}$

143 of each compound. The filtration system was then continuously operated at permeate flux 144 of $3.1 \mathrm{~L} / \mathrm{m}^{2} \mathrm{~h}$ for 5 hours before the first permeate and feed samples were taken for analysis. 145 This was done in order to account for any adsorption of chemicals to the membrane, which 146 may occur predominantly during the initial period of filtration. Compound rejection was 
147 calculated using $R[\%]=\left(1-\frac{C_{p}}{C_{f}}\right) \times 100$, where $C_{p}$ and $C_{f}$ are measured concentrations of

148 the RO permeate and RO feed samples, respectively. The feed pressure and cross-flow

149 velocity during filtration were $950 \mathrm{kPa}$ and $2.1-2.8 \mathrm{~cm} / \mathrm{s}$, respectively.

\section{2.4. Analytical methods}

151 N-nitrosamine concentrations were determined based on the analytical method previously

152 developed by McDonald et al. [24]. The analytical method includes solid phase extraction

153 (SPE) followed by gas chromatography and quantification using tandem mass

154 spectrometry and isotope dilution. Prior to SPE, the N-nitrosamine internal standard stock

155 solution was dosed into each sample $(200 \mathrm{~mL})$ to make up $50 \mathrm{ng} / \mathrm{L}$ of each internal

156 standard concentration. The SPE process was carried out using Supelclean ${ }^{\mathrm{TM}}$ Coconut

157 Charcoal SPE cartridges (Supelco, St Louis, MO, USA). N-nitrosamines were quantified

158 using an Agilent 7890A gas chromatograph coupled with an Agilent 7000B triple

159 quadrupole mass spectrometer. The detection limits of N-nitrosamine concentrations using

160 this technique were $10 \mathrm{ng} / \mathrm{L}$ or lower.

161 All other TrOCs were determined using the method previously reported by Tadkaew et al.

162 [25]. The technique uses SPE followed by quantification by high performance liquid 163 chromatography (HPLC) - tandem mass spectrometry. Prior to SPE, $50 \mathrm{ng}$ deuterated 164 internal standard of each TrOC was added to each $500 \mathrm{~mL}$ sample to account for any 165 variation in recovery during the sample preparation. Each sample was extracted to a $6 \mathrm{~mL}$

166 Oasis HLB SPE cartridge (Waters, Milford, MA, USA). The concentration of TrOCs was

167 quantified using a HPLC system consisting of an Agilent 1200 series HPLC system (Palo 168 Alto, CA, USA) coupled with an API 4000 triple quadrupole mass spectrometer (Applied 169 Biosystems, Foster City, CA, USA). The detection limits of TrOC concentrations using 170 this analytical method were $20 \mathrm{ng} / \mathrm{L}$ or lower. Solution $\mathrm{pH}$, electrical conductivity and 171 temperature were measured using an Orion 4-Star Plus $\mathrm{pH} /$ conductivity meter (Thermo 172 Fisher Scientific, Waltham, MA, USA). 


\section{Results and discussion}

\subsection{Rejection of neutral TrOCs}

175 A total of 11 neutral TrOCs investigated here are hydrophobic $(\log D \geq 2)$, thus they can 176 adsorb onto membranes during the initial stage of filtration, which might lead to overestimation of their rejections. As expected, the measured concentration of these TrOCs in the feed generally decreased as their hydrophobicity increased (Supplementary Material

179 Figure S2). In general, compounds possessing $\log D$ of over 2.5 exhibited very high 180 adsorption (over $40 \%$ reduction in feed concentration). These results indicate that 181 compound adsorption onto the CTA RO membrane can be strongly affected by their hydrophobicity. Concentrations of liuron and triclocarban in the feed solution were

183 determined to be below their detection limits due to the adsorption effects, thus their rejections were excluded from further investigations conducted in this study. Permeate flux during 5 hours of filtration was stable and no evidence of membrane fouling was observed in this study.

In general, the rejection of neutral hydrophilic TrOCs by the CTA RO membrane increased with an increasing order of their molecular weight (Figure 3). The molecular weight cut-off, which refers to the molecular mass of a compound where the membrane have a rejection of greater than $90 \%$, of the CTA RO membrane obtained from the rejection data of hydrophilic compounds (Figure 3a) was $220 \mathrm{Da}$. The results indicate that larger molecules are more likely to be well rejected by the CTA RO membranes. A similar trend was reported with PA RO membranes by Bellona et al [22]. Among the neutral hydrophilic

194 TrOCs used in this investigation, the rejection of seven N-nitrosamines (MW 74-130 $\mathrm{g} / \mathrm{mol}$ ) was particularly low in the range from $25-78 \%$. On the other hand, TrOCs

196 possessing molecular weight over $190 \mathrm{~g} / \mathrm{mol}$ exhibited high rejection values (over 90\%) 197 with simazine (82\%) being the only exception. Similarly, the rejection of neutral

198 hydrophobic compounds generally increased with an increasing order of their molecular weight (Figure 3). Hydrophobic compounds for which molecular weight was over 236 $\mathrm{g} / \mathrm{mol}$ revealed rejections of over 95\%. Notable exceptions include diuron (MW 233 $\mathrm{g} / \mathrm{mol}$ ) which revealed only $39 \%$ rejection, while the rejection of a similar molecular weight compound (carbamazepine, MW $236 \mathrm{~g} / \mathrm{mol}$ ) exhibited over 95\% rejection (Figure 
molecular weight that play an important role in determining compound rejection by a given membrane.

206 Further investigation was carried out by using the other physicochemical parameters of compounds (i.e. molecular volume and minimum projection area) (Figure 4). As a result, an improved correlation was observed between minimum projection area compared to molecular weight or volume of neutral TrOCs and their rejections (Figure 4). In particular, 210 diuron, which has the lowest minimum projection area $\left(28.6 \AA^{2}\right)$ among the neutral 211 hydrophobic TrOCs, also reasonably fit into the correlation (Figure 4c). Given that solutes 212 diffuse within free-volume holes of RO membranes and solutes larger than the free-volume 213 hole-size of RO membranes are unlikely to permeate through a membrane, it is reasonable 214 that the rejection of solutes is governed by their minimum projection area. The results 215 reported here suggest that the rejection of neutral TrOCs can be best predicted using their 216 minimum projection area. Results from Figure 4 also show that the rejection of neutral 217 hydrophobic TrOCs are lower than that of their neutral hydrophilic counterparts with the 218 same molecular weight, volume or minimum projection area. A similar observation has 219 been reported with PA RO membrane [26].

[Figure 3]

\subsection{Rejection of charged TrOCs}

Unlike neutral TrOCs, adsorption of charged TrOCs onto the CTA RO membrane was not observed, with the exception of triclosan (Supplementary Material Figure S3). Triclosan is a hydrophobic-ionogenic compound [27]. Therefore, despite possessing a negative charge, it is still highly hydrophobic ( $\log D=4.57)$. As expected, triclosan concentration in the feed solution decreased to an undetectable level (i.e. $<5 \mathrm{ng} / \mathrm{L}$ ) at the end of the filtration experiment, thus the rejection of triclosan was not calculated or reported.

The rejections of charged TrOCs selected here were commonly very high (over 90\%) with the exception of paracetamol (Figure 5). Paracetamol (MW $151 \mathrm{~g} / \mathrm{mol}$ ) is the smallest molecular weight compound among the charged TrOCs selected in this investigation. No

232 notable difference in rejection between positively and negatively charged TrOCs was 233 observed (Figure 6). The results reported here indicate that the rejection of charged 
compounds is high (i.e. over 90\%) when the minimum projection area of the tested compounds are over $35 \AA^{2}$ (Figure 6), which is similar to the neutral TrOCs (i.e. $40 \AA^{2}$ ) as observed in Figure 4. Although these charged TrOCs selected here has relatively higher molecular weight than the neutral TrOCs, this finding is noteworthy because the electrostatic repulsion which effective to charged TrOCs is expected to significantly enhance their rejection, as previously observed from the PA RO membranes [28]. The zeta potential of the CTA RO membrane used in this study could not be measured because of its very thin hollow fibre configuration. However, the zeta potential of flat sheet CTA membrane obtained from a previous study suggests that the CTA surface (i.e. zeta potential of $-5 \mathrm{mV}$ at $\mathrm{pH}$ 8) [21] has a significantly lower surface charge density than a PA surface (i.e. zeta potential of -25 to $-10 \mathrm{mV}$ at $\mathrm{pH}$ 8) [29, 30]. As a result, the role of electrostatic interaction in removing charged TrOCs by the CTA RO membrane is expected to be less significant compared to PA RO membranes.

\section{[Figure 5]}

\section{[Figure 6]}

\subsection{Rejection of $N$-nitrosamines and inorganics by CTA and PA membranes}

The rejection of N-nitrosamines by the CTA membrane was compared with that by a PA membrane that was previously reported in a pilot-scale study [31]. N-nitrosamines are the smallest compounds of all the neutral TrOCs selected in this study (Table 1), and thus their rejections by the CTA membrane were low (25-78\%). The rejection of N-nitrosamines by the CTA RO membrane (i.e. HKC3023V, Toyobo) generally increased in the increasing order of their minimum projection area, but the two largest N-nitrosamines (i.e. NDPA and NDBA) exhibited low rejections (53\% and 28\%, respectively) (Figure $7 \mathrm{a}$ ). In contrast, the effects of size exclusion for a given PA RO membrane (TFC-HR, Koch Membrane systems) can be identified by a good correlation between the minimum projection area of $\mathrm{N}$-nitrosamines and their rejections (Figure 7a). The results indicate that the rejection of $\mathrm{N}$ nitrosamines by the CTA RO membrane may be affected by molecular properties other than the minimum projection area.

262 Among compound physicochemical properties, $\log D$ of N-nitrosamines exhibited a good 263 correlation with the rejection of high molecular weight $\mathrm{N}$-nitrosamines (i.e. NPYR, NDEA, 264 NPIP, NMOR, NDPA and NDBA) (Figure 7b). Dipole moment of these compounds was 
265 not correlated with their rejections (data not shown). High $\log D$ N-nitrosamines (e.g. 266 NDPA and NDBA) may adsorb more progressively onto the CTA RO membrane surface 267 and the adsorbed $\mathrm{N}$-nitrosamines may subsequently diffuse through the CTA RO 268 membrane without being retained on the membrane surface, leading to a low rejection. 269 Although a complete explanation of their mechanism cannot be provided from the data 270 obtained in this study, it is clear that the rejection of high molecular weight $\mathrm{N}$-nitrosamines 271 (NPYR, NDEA, NPIP, NMOR, NDPA and NDBA) by the CTA RO membrane can be 272 governed by two solute properties (i.e. minimum projection area and hydrophobicity).

273 In addition to the overall rejection trend, the difference in rejection between these two 274 membranes is also of great interest. In general, rejections by the PA RO membrane were 275 higher than those by the CTA RO membrane (Figure 7a). This is somewhat reasonable, 276 considering that the experiments using the PA and CTA RO membranes were conducted 277 under distinctly different permeate fluxes (10 and $3.1 \mathrm{~L} / \mathrm{m}^{2} \mathrm{~h}$, respectively). Permeate flux 278 has been reported to considerably affect the rejection of small $\mathrm{N}$-nitrosamines by PA RO 279 membranes. For example, a previous laboratory-scale study which used a PA RO 280 membrane (ESPA2, Hydranautics) revealed that NDMA rejection increased from 14 to $28138 \%$ with increasing permeate flux from 5 to $10 \mathrm{~L} / \mathrm{m}^{2} \mathrm{~h}$ [30]. This increase in rejection for 282 increased permeate flux can occur for any solutes, since solute flux does not increase as 283 much as solution (i.e. water) flux [32]. In addition, the CTA RO membrane is very likely to 284 be somewhat more "loose" than typical PA RO membranes. For example, the free-volume 285 hole-radius of a CTA RO membrane analysed by positron annihilation techniques was 286 reported to be $0.3 \mathrm{~nm}$ [33], while that of PA RO membranes was $0.20-0.29 \mathrm{~nm}$ [34-36], indicating that the performance of PA RO membrane for neutral compound removal would be expected to be greater than that of a CTA RO membrane.

\section{[Figure 7]}

\section{Conclusions}

291 The rejection behaviours of TrOCs by the hollow fibre CTA RO membrane used in this study were similar to those previously reported for PA RO membranes. In general, the rejection of neutral TrOCs by the CTA RO membrane was strongly affected by their molecular size. Among several physicochemical properties investigated here, the best correlation was obtained between minimum projection area of $\mathrm{TrOCs}$ and their rejections. The rejection of charged TrOCs by the CTA RO membrane was over $90 \%$ with 
paracetamol which has a molecular weight of only $151 \mathrm{~g} / \mathrm{mol}$ being the only exception. There was no apparent difference in rejection between positively and negatively charged TrOCs. The role of electrostatic interaction in removing charged TrOCs by the CTA RO membrane appeared to be less significant compared to PA RO membranes previously reported in literature. Further investigation revealed that the rejection of N-nitrosamines by the CTA RO membrane was strongly affected by their hydrophobicity and molecular size, while that by a PA RO membrane was correlated with molecular size only. The results obtained here indicate that the separation performance of the CTA RO membrane for TrOC removal is comparable with that of PA RO membrane. To evaluate its separation performance during a long-term operation, further investigations will be required focusing on the impact of fouling and chlorination on TrOC rejection. Modelling of TrOC rejection by the CTA RO membrane is also essential as part of future work to predict their rejections during full-scale system operation.

\section{Acknowledgements}

Toyobo Co., Ltd. is thanked for the provision of the membrane module.

\section{References}

[1] M.A. Shannon, P.W. Bohn, M. Elimelech, J.G. Georgiadis, B.J. Marinas, A.M. Mayes, Science and technology for water purification in the coming decades, Nature, 452 (2008) 301-310.

[2] A.A. Alturki, N. Tadkaew, J.A. McDonald, S.J. Khan, W.E. Price, L.D. Nghiem, Combining MBR and NF/RO membrane filtration for the removal of trace organics in indirect potable water reuse applications, J. Membr. Sci., 365 (2010) 206-215.

[3] T. Fujioka, S.J. Khan, Y. Poussade, J.E. Drewes, L.D. Nghiem, N-nitrosamine removal by reverse osmosis for indirect potable water reuse - A critical review based on observations from laboratory-, pilot- and full-scale studies, Sep. Purif. Technol., 98 (2012) 503-515.

[4] A. Simon, L.D. Nghiem, P. Le-Clech, S.J. Khan, J.E. Drewes, Effects of membrane degradation on the removal of pharmaceutically active compounds (PhACs) by NF/RO filtration processes, J. Membr. Sci., 340 (2009) 16-25.

[5] J. Glater, S.-k. Hong, M. Elimelech, The search for a chlorine-resistant reverse osmosis membrane, Desalination, 95 (1994) 325-345.

[6] M.J. Farré, K. Döderer, L. Hearn, Y. Poussade, J. Keller, W. Gernjak, Understanding the operational parameters affecting NDMA formation at Advanced Water Treatment Plants, J. Hazard. Mater., 185 (2011) 1575-1581.

[7] M.H. Plumlee, M. López-Mesas, A. Heidlberger, K.P. Ishida, M. Reinhard, Nnitrosodimethylamine (NDMA) removal by reverse osmosis and UV treatment and analysis via LC-MS/MS, Water Res., 42 (2008) 347-355. 
[8] S.J. Khan, J.A. McDonald, Quantifying human exposure to contaminants for multiple-barrier water reuse systems, Water Sci. Technol., 61 (2010) 77-83.

[9] T. Fujioka, S.J. Khan, J.A. McDonald, A. Roux, Y. Poussade, J.E. Drewes, L.D. Nghiem, N-nitrosamine rejection by reverse osmosis membranes: A full-scale study, Water Res., 47 (2013) 6141-6148.

[10] M. Krauss, P. Longrée, E. van Houtte, J. Cauwenberghs, J. Hollender, Assessing the fate of Nitrosamine precursors in wastewater treatment by physicochemical fractionation, Environ. Sci. Technol., 44 (2010) 7871-7877.

[11] J. Choi, R.L. Valentine, Formation of N-nitrosodimethylamine (NDMA) from reaction of monochloramine: a new disinfection by-product, Water Res., 36 (2002) 817-824.

[12] K.P. Lee, T.C. Arnot, D. Mattia, A review of reverse osmosis membrane materials for desalination-Development to date and future potential, J. Membr. Sci., 370 (2011) 1-22.

[13] S. Konagaya, K. Nita, Y. Matsui, M. Miyagi, New chlorine-resistant polyamide reverse osmosis membrane with hollow fiber configuration, Journal of Applied Polymer Science, 79 (2001) 517-527.

[14] N. Fujiwara, H. Matsuyama, Elimination of biological fouling in seawater reverse osmosis desalination plants, Desalination, 227 (2008) 295-305.

[15] J. Xu, G. Ruan, L. Zou, C. Gao, Effect of chlorine and acid injection on hollow fiber RO for SWRO, Desalination, 262 (2010) 115-120.

[16] N. Fujiwara, H. Matsuyama, Optimization of the intermittent chlorine injection (ICI) method for seawater desalination RO plants, Desalination, 229 (2008) 231244.

[17] A. Munoz Elguera, A. Nunez, M. Nishida, Experimental test of TOYOBO membranes for seawater desalination at Las Palmas, Spain, Desalination, 125 (1999) 55-64.

[18] J.A.M.H. Hofman, E.F. Beerendonk, H.C. Folmer, J.C. Kruithof, Removal of pesticides and other micropollutants with cellulose-acetate, polyamide and ultralow pressure reverse osmosis membranes, Desalination, 113 (1997) 209-214.

[19] R.M. Narbaitz, D. Rana, H.T. Dang, J. Morrissette, T. Matsuura, S.Y. Jasim, S. Tabe, P. Yang, Pharmaceutical and personal care products removal from drinking water by modified cellulose acetate membrane: Field testing, Chem. Eng. J., 225 (2013) 848-856.

[20] P. Xu, J.E. Drewes, T.-U. Kim, C. Bellona, G. Amy, Effect of membrane fouling on transport of organic contaminants in NF/RO membrane applications, J. Membr. Sci., 279 (2006) 165-175.

[21] A.A. Alturki, J.A. McDonald, S.J. Khan, W.E. Price, L.D. Nghiem, M. Elimelech, Removal of trace organic contaminants by the forward osmosis process, Sep. Purif. Technol., 103 (2013) 258-266.

[22] C. Bellona, J.E. Drewes, P. Xu, G. Amy, Factors affecting the rejection of organic solutes during NF/RO treatment - A literature review, Water Res., 38 (2004) 27952809. 
[23] B. Van der Bruggen, A. Verliefde, L. Braeken, E.R. Cornelissen, K. Moons, J.Q.J.C. Verberk, H.J.C. van Dijk, G. Amy, Assessment of a semi-quantitative method for estimation of the rejection of organic compounds in aqueous solution in nanofiltration, J. Chem. Technol. Biotechnol., 81 (2006) 1166-1176.

[24] J.A. McDonald, N.B. Harden, L.D. Nghiem, S.J. Khan, Analysis of N-nitrosamines in water by isotope dilution gas chromatography-electron ionisation tandem mass spectrometry, Talanta, 99 (2012) 146-152.

[25] N. Tadkaew, F.I. Hai, J.A. McDonald, S.J. Khan, L.D. Nghiem, Removal of trace organics by MBR treatment: The role of molecular properties, Water Res., 45 (2011) 2439-2451.

[26] L.D. Nghiem, A.I. Schäfer, M. Elimelech, Removal of natural hormones by nanofiltration membranes: Measurement, modeling, and mechanisms, Environ. Sci. Technol., 38 (2004) 1888-1896.

[27] L.D. Nghiem, P.J. Coleman, NF/RO filtration of the hydrophobic ionogenic compound triclosan: Transport mechanisms and the influence of membrane fouling, Sep. Purif. Technol., 62 (2008) 709-716.

[28] L.D. Nghiem, A.I. Schäfer, M. Elimelech, Role of electrostatic interactions in the retention of pharmaceutically active contaminants by a loose nanofiltration membrane, J. Membr. Sci., 286 (2006) 52-59.

[29] T. Fujioka, L.D. Nghiem, S.J. Khan, J.A. McDonald, Y. Poussade, J.E. Drewes, Effects of feed solution characteristics on the rejection of N-nitrosamines by reverse osmosis membranes, J. Membr. Sci., 409-410 (2012) 66-74.

[30] T. Fujioka, S.J. Khan, J.A. McDonald, A. Roux, Y. Poussade, J.E. Drewes, L.D. Nghiem, N-nitrosamine rejection by nanofiltration and reverse osmosis membranes: The importance of membrane characteristics, Desalination, 316 (2013) $67-75$.

[31] T. Fujioka, S.J. Khan, J.A. McDonald, A. Roux, Y. Poussade, J.E. Drewes, L.D. Nghiem, Rejection of small solutes by reverse osmosis membranes for water reuse applications: A pilot-scale study, Submitted to Desalination.

[32] J.G. Wijmans, R.W. Baker, The solution-diffusion model: a review, J. Membr. Sci., 107 (1995) 1-21.

[33] H. Hagihara, K. Ito, N. Oshima, A. Yabuuchi, H. Suda, H. Yanagishita, Depth profiling of the free-volume holes in cellulose triacetate hollow-fiber membranes for reverse osmosis by means of variable-energy positron annihilation lifetime spectroscopy, Desalination, 344 (2014) 86-89.

[34] Z. Chen, K. Ito, H. Yanagishita, N. Oshima, R. Suzuki, Y. Kobayashi, Correlation study between free-volume holes and molecular separations of composite membranes for reverse osmosis processes by means of variable-energy positron annihilation techniques, J. Phys. Chem. C, 115 (2011) 18055-18060.

[35] T. Fujioka, N. Oshima, R. Suzuki, S.J. Khan, A. Roux, Y. Poussade, J.E. Drewes, L.D. Nghiem, Rejection of small and uncharged chemicals of emerging concern by reverse osmosis membranes: The role of free volume space within the active skin layer, Sep. Purif. Technol., 116 (2013) 426-432. 
[36] K. Ito, Z. Chen, W. Zhou, N. Oshima, H. Yanagishita, R. Suzuki, Y. Kobayashi, Subnanoscopic Holes in Composite Membranes for Desalination Elucidated by Energy-Tunable Positron Annihilation, Jpn. J. Poly. Sci. Technol., 69 (2012) 443447. 
424 Table 1: Physicochemical characteristics of the selected TrOCs.

\begin{tabular}{|c|c|c|c|c|}
\hline Compound & $\begin{array}{l}\text { Molecular } \\
\text { weight } \\
{[\mathrm{g} / \mathrm{mol}]}\end{array}$ & $\begin{array}{l}\log D^{\mathrm{a}} \\
{[-]}\end{array}$ & $\begin{array}{l}\mathrm{pK}_{\mathrm{a}}\left(\mathrm{pK}_{\mathrm{b}}\right)^{\mathrm{a}} \\
{[-]}\end{array}$ & $\begin{array}{l}\text { Minimum } \\
\text { projection } \\
\text { area }^{\mathrm{a}}\left[\AA^{2}\right]\end{array}$ \\
\hline \multicolumn{5}{|l|}{ Neutral hydrophilic } \\
\hline N-nitrosodimethylamine (NDMA) & 74.1 & 0.04 & (3.5) & 19.5 \\
\hline N-nitrosomethylethylamine (NMEA) & 88.1 & 0.40 & (3.4) & 22.1 \\
\hline N-nitrosopyrrolidine (NPYR) & 100.1 & 0.44 & (3.3) & 25.0 \\
\hline N-nitrosodiethylamine (NDEA) & 102.1 & 0.75 & (3.3) & 25.4 \\
\hline N-nitrosopiperidine (NPIR) & 114.1 & 0.89 & (3.3) & 27.2 \\
\hline N-nitrosomorpholine (NMOR) & 116.1 & -0.18 & $(3.1)$ & 25.2 \\
\hline N-nitrosodipropylamine (NDPA) & 130.1 & 1.80 & (3.3) & 28.3 \\
\hline Caffeine & 194.2 & -0.55 & $(0.9)$ & 30.0 \\
\hline Simazine & 201.7 & 1.78 & (3.2) & 35.8 \\
\hline Atrazine & 215.7 & 1.32 & 9.6 & 40.0 \\
\hline Primidone & 218.3 & 1.12 & 11.5 & 42.7 \\
\hline Meprobamate & 218.3 & 0.93 & 15.2 & 45.8 \\
\hline Triamterene & 253.3 & 1.11 & (3.1) & 35.2 \\
\hline Trimethoprim & 290.3 & 1.28 & $(7.2)$ & 51.1 \\
\hline \multicolumn{5}{|l|}{ Neutral hydrophobic } \\
\hline N-nitrosodi-n-butylamine (NDBA) & 158.1 & 2.69 & $(3.3)$ & 28.8 \\
\hline N,N-Diethyl-meta-toluamide (DEET) & 191.3 & 2.50 & $(0.1)$ & 40.1 \\
\hline Bisphenol A & 228.3 & 4.04 & $9.8 ; 10.4$ & 44.0 \\
\hline Diuron & 233.1 & 2.53 & 13.2 & 28.6 \\
\hline Carbamazepine & 236.3 & 2.77 & 16.0 & 38.8 \\
\hline Linuron & 249.1 & 2.68 & 12.0 & 30.8 \\
\hline Diazepam & 284.7 & 3.08 & (2.9) & 47.3 \\
\hline Triclocarban & 315.6 & 4.93 & 11.4 & 50.1 \\
\hline Clozapine & 326.3 & 3.40 & $(7.4)$ & 55.5 \\
\hline Omeprazole & 345.4 & 2.43 & $(4.8) ; 9.3$ & 43.5 \\
\hline Hydroxyzine & 374.9 & 3.24 & $(2.1,7.8)$ & 64.7 \\
\hline \multicolumn{5}{|l|}{ Negatively charged } \\
\hline Paracetamol & 151.2 & 0.91 & 7.1 & 23.7 \\
\hline Ibuprofen & 206.3 & 0.97 & 4.9 & 35.4 \\
\hline Naproxen & 230.3 & -0.16 & 4.2 & 34.8 \\
\hline Gemfibrozil & 250.3 & 1.33 & 4.4 & 43.4 \\
\hline Dilantin & 252.3 & 0.91 & 6.5 & 47.8 \\
\hline Sulfamethoxazole & 253.3 & 0.39 & 7.7 & 45.2 \\
\hline Ketoprofen & 254.3 & 0.48 & 3.9 & 43.0 \\
\hline Triclosan & 289.5 & 4.57 & 7.7 & 40.0 \\
\hline Diclofenac & 296.1 & 1.16 & 4.0 & 43.3 \\
\hline Enalapril & 376.5 & -0.91 & $3.7 ;(5.2)$ & 59.8 \\
\hline Simvastatin hydroxy acid & 436.6 & 0.63 & 4.2 & 68.1 \\
\hline \multicolumn{5}{|l|}{ Zwitterion } \\
\hline Tris(2-carboxyethyl)phosphine (TCEP) & 250.2 & -10.4 & $3.2 ;(9.0)$ & 51.1 \\
\hline \multicolumn{5}{|l|}{ Positively charged } \\
\hline Atenolol & 266.3 & -1.18 & $(9.7)$ & 36.9 \\
\hline Amitriptyline & 277.4 & 3.02 & $(9.8)$ & 58.8 \\
\hline Fluoxetine & 309.3 & 2.46 & $(9.8)$ & 44.3 \\
\hline Verapamil & 454.6 & 3.44 & $(9.7)$ & 81.2 \\
\hline
\end{tabular}

${ }^{\mathrm{a}}$ Chemaxon (http://www.chemicalize.org/). 


\section{LIST OF FIGURES}

427 Figure 1: (a) Schematic structure of the HKC3023V membrane module and (b) schematic 428 diagram of the cross flow RO filtration system.

429 Figure 2: Schematic figure of minimum projection area. The line perpendicular to the circular 430 disk represents the centre axis of the minimum projection area.

431 Figure 3: Rejection of neutral (a) hydrophilic and (b) hydrophobic TrOCs (20 mM NaCl, 1 $432 \mathrm{mM} \mathrm{NaHCO}_{3}, 1 \mathrm{mM} \mathrm{CaCl}_{2}$, feed pressure $1.05 \mathrm{MPa}$, permeate flux $3.1 \mathrm{~L} / \mathrm{m}^{2} \mathrm{~h}$, feed $\mathrm{pH} 8.0 \pm$ 4330.1 , feed temperature $\left.20.0 \pm 0.1^{\circ} \mathrm{C}\right)$. The molecular weight $(\mathrm{g} / \mathrm{mol})$ is shown in the 434 parentheses. Values reported here are the average and ranges of duplicate samples.

435 Figure 4: Rejection of neutral TrOCs as a function of (a) their molecular weight, (b) 436 molecular volume, and (c) minimal projection area. Experimental conditions are described in 437 Figure 3. Values reported here are the average and ranges of duplicate samples.

438 Figure 5: Rejection of charged TrOCs $(20 \mathrm{mM} \mathrm{NaCl}, 1 \mathrm{mM} \mathrm{NaHCO} 3,1 \mathrm{mM} \mathrm{CaCl}$, feed 439 pressure $1.05 \mathrm{MPa}$, permeate flux $3.1 \mathrm{~L} / \mathrm{m}^{2} \mathrm{~h}$, feed $\mathrm{pH} 8.0 \pm 0.1$, feed temperature $20.0 \pm$ $\left.4400.1^{\circ} \mathrm{C}\right)$. The molecular weight $(\mathrm{g} / \mathrm{mol})$ is shown in the parentheses. Values reported here are 441 the average and ranges of duplicate samples.

442 Figure 6: Rejection of charged TrOCs as a function of their minimum projection area. 443 Experimental conditions are described in Figure 5. Values reported here are the average and 444 ranges of duplicate samples.

445 Figure 7: N-nitrosamine rejection by the CTA (HKC3023V) and PA (TFC-HR) RO 446 membranes as a function of their (a) minimum projection area and (b) $\log D(20 \mathrm{mM} \mathrm{NaCl}, 1$ $447 \mathrm{mM} \mathrm{NaHCO} 3,1 \mathrm{mM} \mathrm{CaCl}$, feed $\mathrm{pH} 8.0 \pm 0.1$, feed temperature $20.0 \pm 0.1{ }^{\circ} \mathrm{C}$ ). Values 448 reported here are the average and ranges of duplicate samples. The rejection data by the CTA 449 membrane was obtained with permeate flux $3.1 \mathrm{~L} / \mathrm{m}^{2} \mathrm{~h}$ and recovery $25 \%$. The rejection data 450 by the PA membrane was reported by Fujioka et al. [30] (three of 4-inch membrane elements, 451 permeate flux $10 \mathrm{~L} / \mathrm{m}^{2} \mathrm{~h}$ and recovery $25 \%$ ) where NDBA rejection data is not available. 
(a)

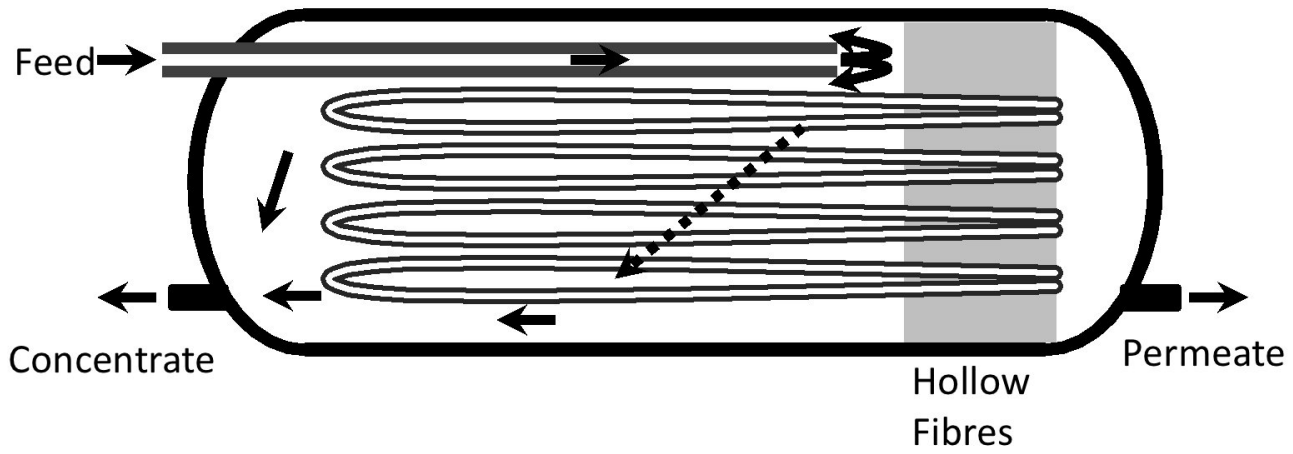

(b) Flowmeter

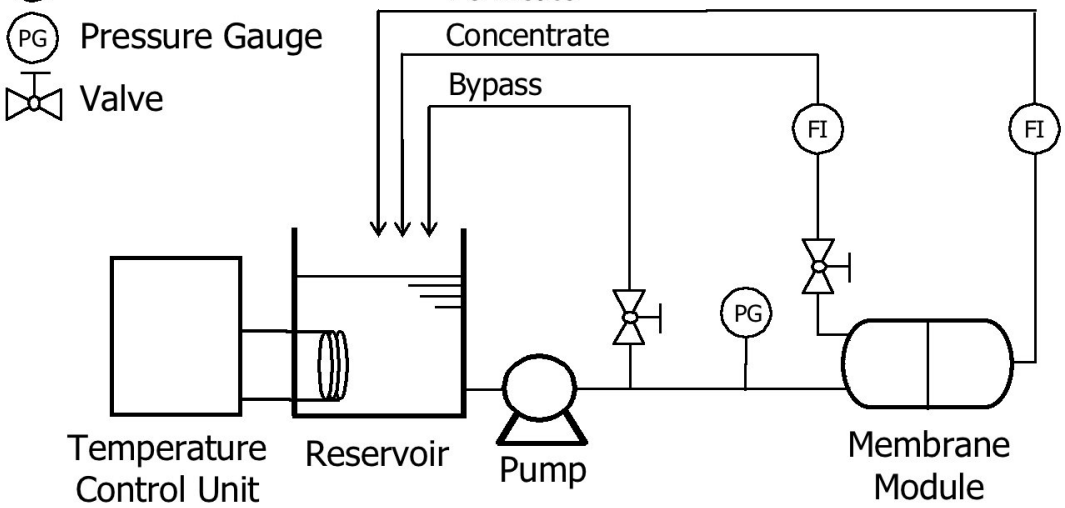

$453 \quad$ Figure 1 


$$
\alpha
$$




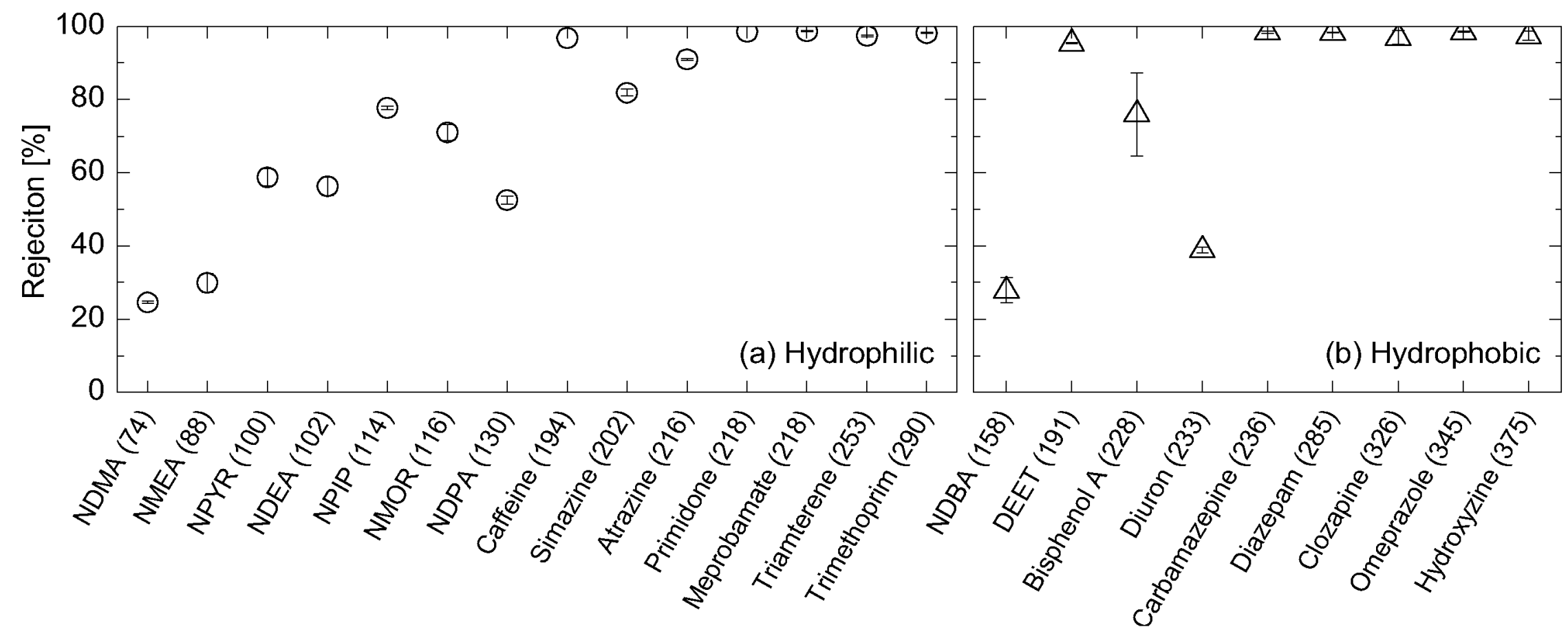

457 Figure 3 


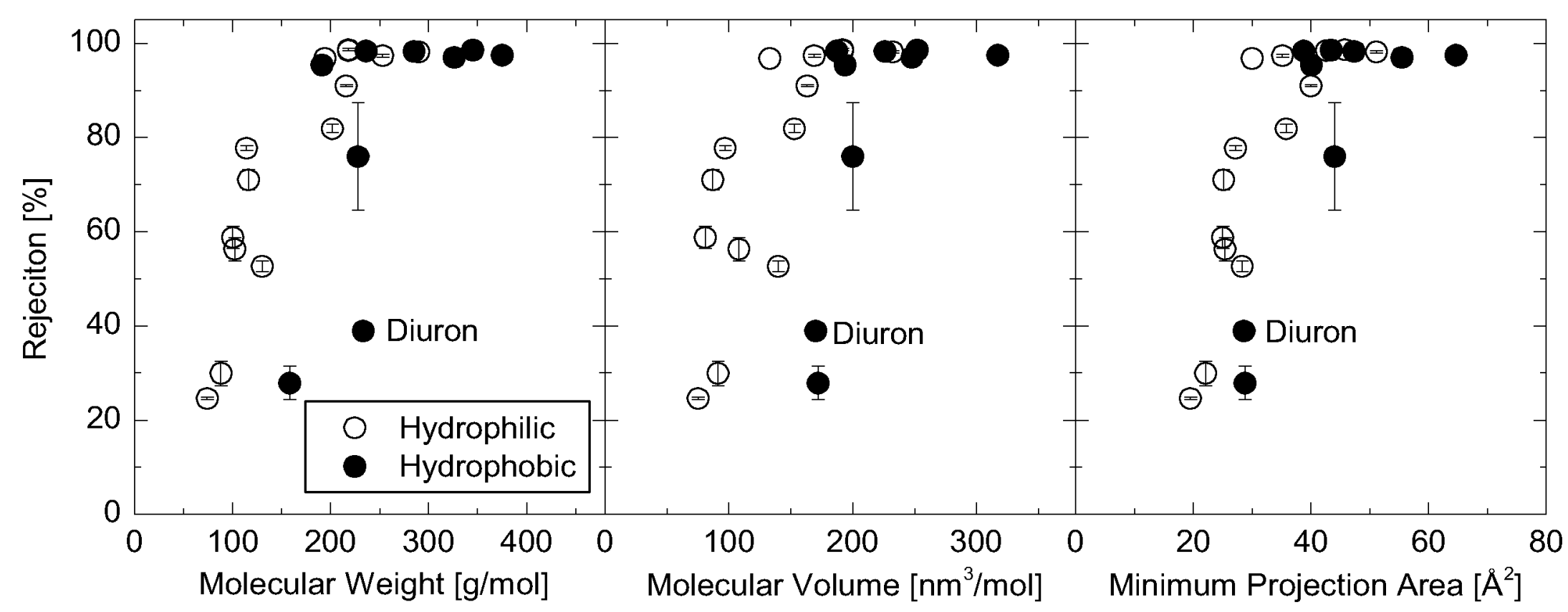

458

$459 \quad$ Figure 4 


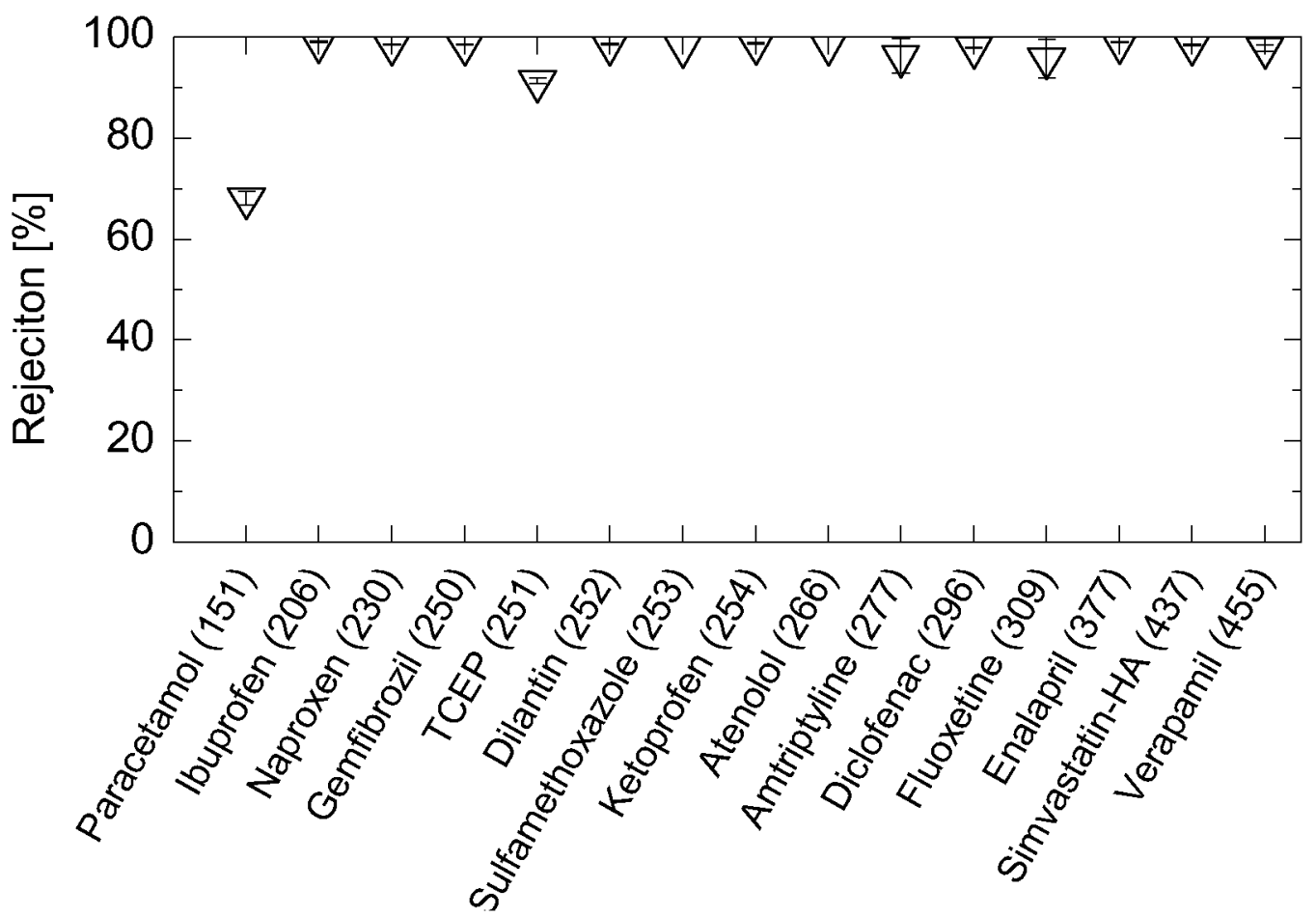

460

$461 \quad$ Figure 5 


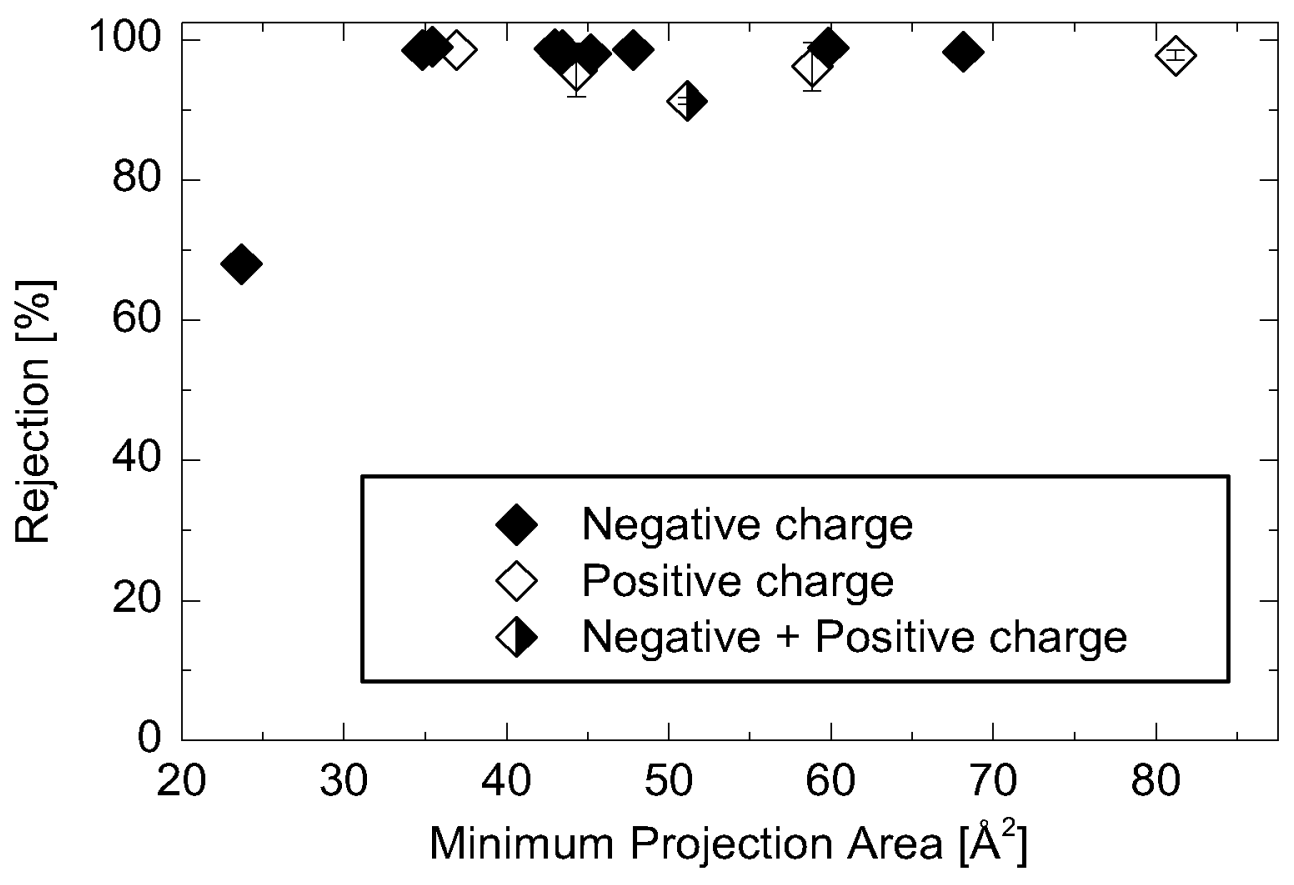

462

$463 \quad$ Figure 6 


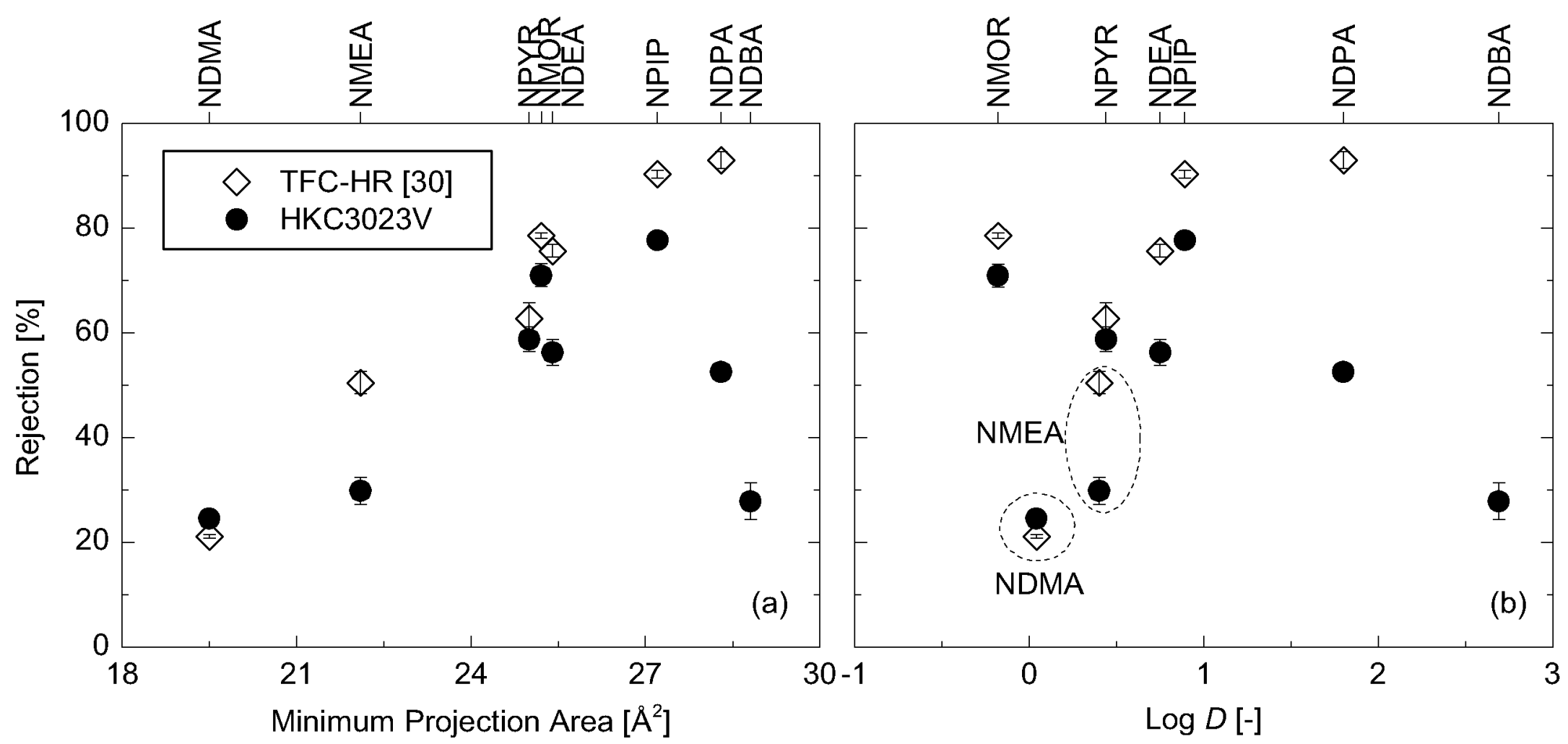

$465 \quad$ Figure 7 


\title{
Rejection of trace organic chemicals by a hollow fibre cellulose triacetate reverse osmosis membrane
}

\author{
Takahiro Fujioka ${ }^{1, *}$, Stuart J. Khan ${ }^{2}$, James A. McDonald ${ }^{2}$, Long D. Nghiem ${ }^{1}$ \\ ${ }^{1}$ Strategic Water Infrastructure Laboratory, School of Civil Mining and Environmental \\ Engineering, The University of Wollongong, NSW 2522, Australia \\ ${ }^{2}$ UNSW Water Research Centre, School of Civil and Environmental Engineering, The \\ University of New South Wales, NSW 2052, Australia
}

\section{SUPPLEMENTARY MATERIAL}

* Corresponding author: Takahiro Fujioka, Email: takahiro@uow.edu.au, Ph +61 242214074 
1 Table S1: Physicochemical properties of the selected TrOCs.

\begin{tabular}{|c|c|c|c|c|}
\hline Compound & Formula & $\begin{array}{l}\text { Distribution of } \\
\text { charged spieces at } \\
\mathrm{pH} 8^{\mathrm{a}}[\%]\end{array}$ & $\begin{array}{l}\text { Molecualr } \\
\text { volume } \\
{\left[\mathrm{nm}^{3} / \mathrm{mol}\right]}\end{array}$ & $\begin{array}{l}\text { Dipole } \\
\text { moment }^{\mathrm{c}} \\
\text { [Debye] }^{\text {Debe }}\end{array}$ \\
\hline \multicolumn{5}{|l|}{ Neutral hydrophilic } \\
\hline N-nitrosodimethylamine & $\mathrm{C}_{2} \mathrm{H}_{6} \mathrm{~N}_{2} \mathrm{O}$ & 0 & 75 & 3.71 \\
\hline N-nitrosomethylethylamine & $\mathrm{C}_{2} \mathrm{H}_{8} \mathrm{~N}_{2} \mathrm{O}$ & 0 & 91 & 3.71 \\
\hline $\mathrm{N}$-nitrosopyrrolidine & $\mathrm{C}_{4} \mathrm{H}_{8} \mathrm{~N}_{2} \mathrm{O}$ & 0 & 81 & 3.74 \\
\hline $\mathrm{N}$-nitrosodiethylamine & $\mathrm{C}_{4} \mathrm{H}_{10} \mathrm{~N}_{2} \mathrm{O}$ & 0 & 108 & 3.72 \\
\hline $\mathrm{N}$-nitrosopiperidine & $\mathrm{C}_{5} \mathrm{H}_{10} \mathrm{~N}_{2} \mathrm{O}$ & 0 & 97 & 3.73 \\
\hline N-nitrosomorpholine & $\mathrm{C}_{4} \mathrm{H}_{8} \mathrm{~N}_{2} \mathrm{O}_{2}$ & 0 & 87 & 2.68 \\
\hline N-nitrosodipropylamine & $\mathrm{C}_{6} \mathrm{H}_{14} \mathrm{~N}_{2} \mathrm{O}$ & 0 & 140 & 3.77 \\
\hline Caffeine & $\mathrm{C}_{8} \mathrm{H}_{10} \mathrm{~N}_{4} \mathrm{O}_{2}$ & 0 & 133 & 2.24 \\
\hline Simazine & $\mathrm{C}_{7} \mathrm{H}_{12} \mathrm{ClN}_{5}$ & 0 & 153 & 2.29 \\
\hline Atrazine & $\mathrm{C}_{8} \mathrm{H}_{14} \mathrm{ClN}_{5}$ & 33 & 163 & 4.03 \\
\hline Primidone & $\mathrm{C}_{12} \mathrm{H}_{14} \mathrm{~N}_{2} \mathrm{O}_{2}$ & 0 & 192 & 3.69 \\
\hline Meprobamate & $\mathrm{C}_{9} \mathrm{H}_{18} \mathrm{~N}_{2} \mathrm{O}_{4}$ & 0 & 192 & 2.82 \\
\hline Triamterene & $\mathrm{C}_{12} \mathrm{H}_{11} \mathrm{~N}_{7}$ & 0 & 169 & 1.33 \\
\hline Trimethoprim & $\mathrm{C}_{14} \mathrm{H}_{18} \mathrm{~N}_{4} \mathrm{O}_{3}$ & 12 & 232 & 4.34 \\
\hline \multicolumn{5}{|l|}{ Neutral hydrophobic } \\
\hline N-nitrosodi-n-butylamine & $\mathrm{C}_{8} \mathrm{H}_{18} \mathrm{~N}_{2} \mathrm{O}$ & 0 & 172 & 3.82 \\
\hline N,N-Diethyl-meta-toluamide & $\mathrm{C}_{12} \mathrm{H}_{17} \mathrm{NO}$ & 0 & 194 & 3.14 \\
\hline Bisphenol A & $\mathrm{C}_{15} \mathrm{H}_{16} \mathrm{O}_{2}$ & 2 & 200 & 1.85 \\
\hline Diuron & $\mathrm{C}_{9} \mathrm{H}_{10} \mathrm{Cl}_{2} \mathrm{~N}_{2} \mathrm{O}$ & 0 & 170 & 4.32 \\
\hline Carbamazepine & $\mathrm{C}_{15} \mathrm{H}_{12} \mathrm{~N}_{2} \mathrm{O}$ & 0 & 187 & 3.52 \\
\hline Linuron & $\mathrm{C}_{9} \mathrm{H}_{10} \mathrm{Cl}_{2} \mathrm{~N}_{2} \mathrm{O}_{2}$ & 0 & 177 & 4.52 \\
\hline Diazepam & $\mathrm{C}_{16} \mathrm{H}_{13} \mathrm{ClN}_{2} \mathrm{O}$ & 0 & 226 & 1.88 \\
\hline Triclocarban & $\mathrm{C}_{13} \mathrm{H}_{9} \mathrm{C}_{13} \mathrm{~N}_{2} \mathrm{O}$ & 0 & 206 & 4.41 \\
\hline Clozapine & $\mathrm{C}_{18} \mathrm{H}_{19} \mathrm{ClN}_{4}$ & 18 & 248 & 1.62 \\
\hline Omeprazole & $\mathrm{C}_{17} \mathrm{H}_{19} \mathrm{~N}_{3} \mathrm{O}_{3} \mathrm{~S}$ & 2 & 252 & 4.53 \\
\hline Hydroxyzine & $\mathrm{C}_{21} \mathrm{H}_{27} \mathrm{ClN}_{2} \mathrm{O}_{2}$ & 40 & 317 & 0.91 \\
\hline \multicolumn{5}{|l|}{ Negative Charge } \\
\hline Paracetamol & $\mathrm{C}_{8} \mathrm{H}_{9} \mathrm{NO}_{2}$ & 89 & 131 & 0.48 \\
\hline Ibuprofen & $\mathrm{C}_{13} \mathrm{H}_{18} \mathrm{O}_{2}$ & 100 & 200 & 1.68 \\
\hline Naproxen & $\mathrm{C}_{14} \mathrm{H}_{14} \mathrm{O}_{3}$ & 100 & 192 & 1.38 \\
\hline Gemfibrozil & $\mathrm{C}_{15} \mathrm{H}_{22} \mathrm{O}_{3}$ & 100 & 240 & 0.65 \\
\hline Dilantin & $\mathrm{C}_{15} \mathrm{H}_{12} \mathrm{~N}_{2} \mathrm{O}_{2}$ & 97 & 201 & 2.18 \\
\hline Sulfamethoxazole & $\mathrm{C}_{10} \mathrm{H}_{11} \mathrm{~N}_{3} \mathrm{O}_{3} \mathrm{~S}$ & 69 & 173 & 4.71 \\
\hline Ketoprofen & $\mathrm{C}_{16} \mathrm{H}_{14} \mathrm{O}_{3}$ & 100 & 212 & 3.27 \\
\hline Triclosan & $\mathrm{C}_{12} \mathrm{H}_{7} \mathrm{Cl}_{3} \mathrm{O}_{2}$ & 68 & 194 & 2.95 \\
\hline Diclofenac & $\mathrm{C}_{14} \mathrm{H}_{11} \mathrm{Cl}_{2} \mathrm{NO}_{2}$ & 100 & 207 & 1.67 \\
\hline Enalapril & $\mathrm{C}_{20} \mathrm{H}_{28} \mathrm{~N}_{2} \mathrm{O}_{5}$ & 100 & 313 & 4.59 \\
\hline Simvastatin hydroxy acid & $\mathrm{C}_{25} \mathrm{H}_{40} \mathrm{O}_{6}$ & 100 & 384 & 5.24 \\
\hline \multicolumn{5}{|l|}{ Zwitterion } \\
\hline \multicolumn{5}{|l|}{ Positive Charge } \\
\hline Atenolol & $\mathrm{C}_{14} \mathrm{H}_{22} \mathrm{~N}_{2} \mathrm{O}_{3}$ & 98 & 237 & 4.92 \\
\hline Amitriptyline & $\mathrm{C}_{20} \mathrm{H}_{23} \mathrm{~N}$ & 98 & 258 & 0.52 \\
\hline Fluoxetine & $\mathrm{C}_{17} \mathrm{H}_{18} \mathrm{~F}_{3} \mathrm{NO}$ & 98 & 267 & 1.31 \\
\hline Verapamil & $\mathrm{C}_{27} \mathrm{H}_{38} \mathrm{~N}_{2} \mathrm{O}_{4}$ & 98 & 429 & 7.04 \\
\hline
\end{tabular}

2 Chemaxon (http://www.chemicalize.org/).

$3{ }^{\mathrm{b}}$ Chemspider (http://www.chemspider.com/), data calculated using Advanced Chemistry

4 Development (ACD/Labs).

$5 \quad{ }^{\mathrm{c}}$ Millsian 2.1 Software (Millsian UNC). 


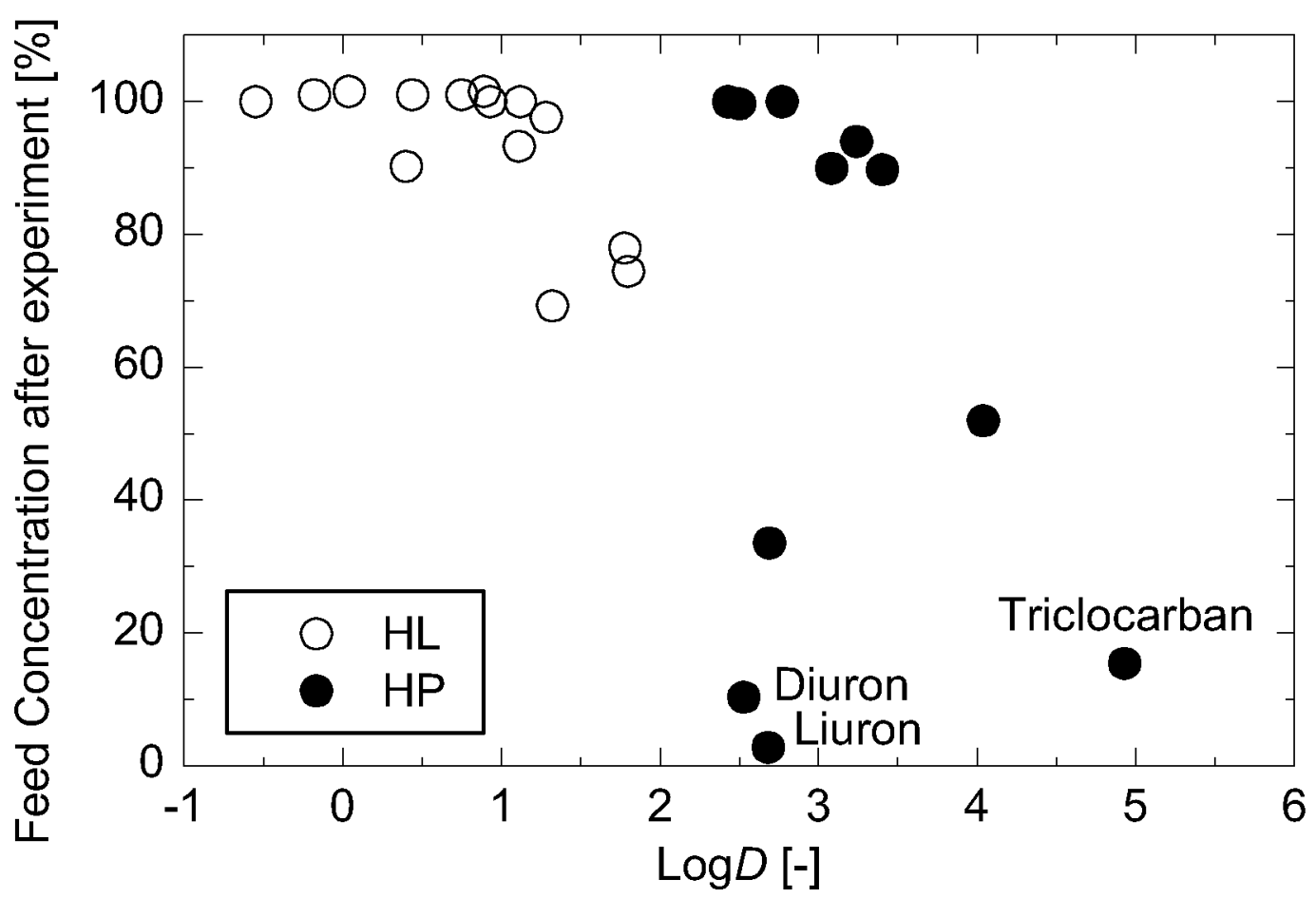

6

7 Figure S2: Reduction of feed concentration of neutral TrOCs as a function of $\log D$ after 5 8 hours filtration $\left(20 \mathrm{mM} \mathrm{NaCl}, 1 \mathrm{mM} \mathrm{NaHCO}_{3}, 1 \mathrm{mM} \mathrm{CaCl}_{2}\right.$, feed pressure $1.05 \mathrm{MPa}$, 9 permeate flux $3.1 \mathrm{~L} / \mathrm{m}^{2} \mathrm{~h}$, feed $\mathrm{pH} 8.0 \pm 0.1$, feed temperature $20.0 \pm 0.1^{\circ} \mathrm{C}$ ). $\mathrm{HL}$ and $\mathrm{HP}$ 10 represents hydrophilic and hydrophobic compounds, respectively. 


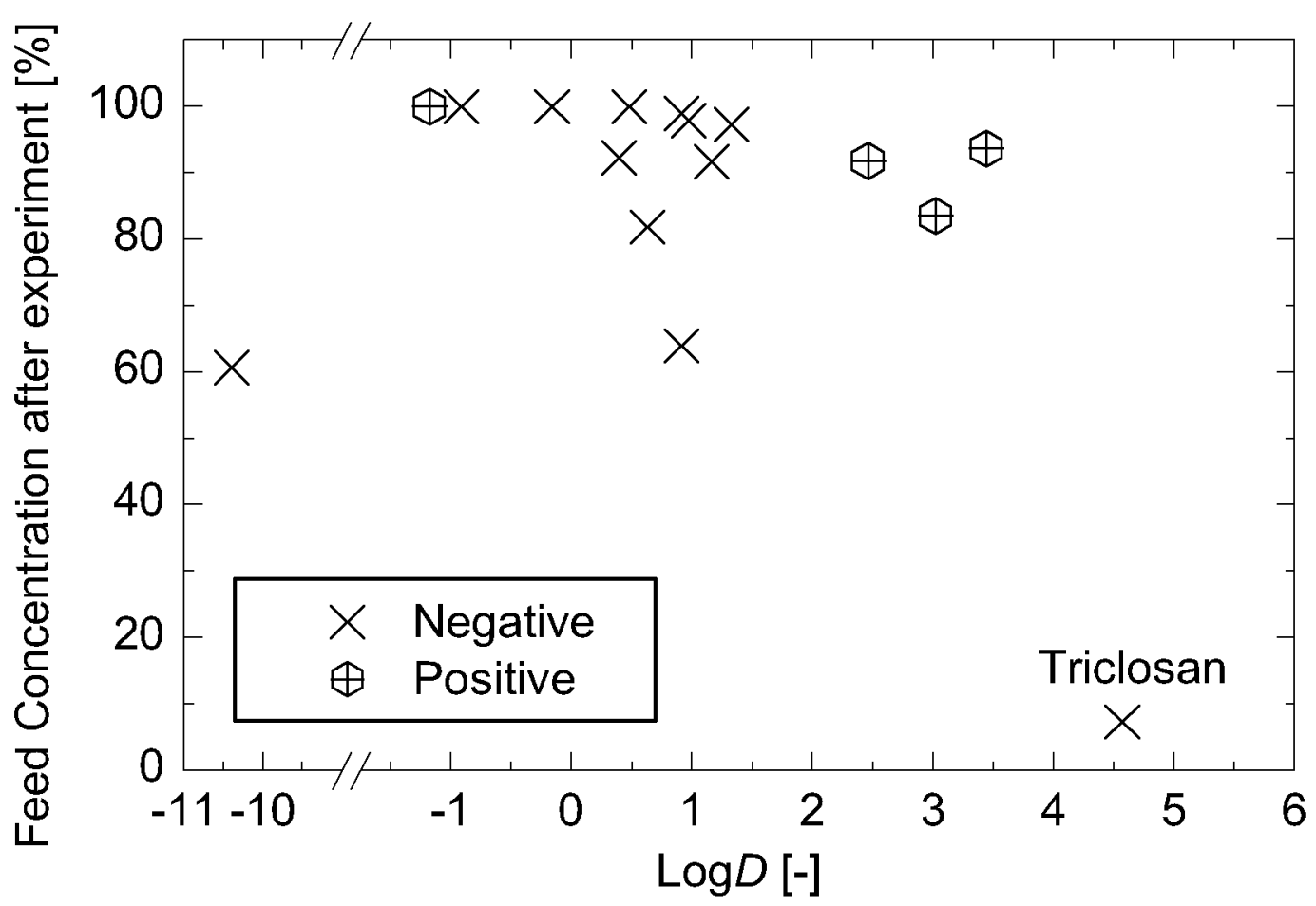

11

12 Figure S3: Reduction of feed concentration of charged TrOCs as a function of $\log D$ after 5 13 hours filtration $\left(20 \mathrm{mM} \mathrm{NaCl}, 1 \mathrm{mM} \mathrm{NaHCO}, 1 \mathrm{mM} \mathrm{CaCl}_{2}\right.$, feed pressure $1.05 \mathrm{MPa}$, 14 permeate flux $3.1 \mathrm{~L} / \mathrm{m}^{2} \mathrm{~h}$, feed $\mathrm{pH} 8.0 \pm 0.1$, feed temperature $20.0 \pm 0.1^{\circ} \mathrm{C}$ ). 